\title{
Controlled dehydration of a ruthenium complex-DNA crystal induces reversible DNA kinking
}

Article

Accepted Version

Hall, J. P., Sanchez-Weatherby, J., Alberti, C., Hurtado Quimper, C., O'Sullivan, K., Brazier, J. A., Winter, G., Sorensen, T., Kelly, J. M., Cardin, D. J. and Cardin, C. J. (2014) Controlled dehydration of a ruthenium complex-DNA crystal induces reversible DNA kinking. Journal of the American Chemical Society, 136 (50). pp. 17505-17512. ISSN 0002-7863 doi: https://doi.org/10.1021/ja508745x Available at https://centaur.reading.ac.uk/40118/

It is advisable to refer to the publisher's version if you intend to cite from the work. See Guidance on citing.

Published version at: http://pubs.acs.org/doi/abs/10.1021/ja508745x

To link to this article DOI: http://dx.doi.org/10.1021/ja508745x

Publisher: American Chemical Society

All outputs in CentAUR are protected by Intellectual Property Rights law, including copyright law. Copyright and IPR is retained by the creators or other copyright holders. Terms and conditions for use of this material are defined in the End User Agreement. 


\section{CentAUR}

Central Archive at the University of Reading

Reading's research outputs online 


\title{
Controlled dehydration of a ruthenium complex-DNA crystal induces reversible DNA kinking
}

James. P. Hall ${ }^{1,2}$, Juan Sanchez-Weatherby ${ }^{2}$, Cora Alberti ${ }^{1}$, Caroline Hurtado Quimper ${ }^{1}$, Kyra O'Sullivan ${ }^{3}$, John. A. Brazier $^{4}$, Graeme Winter ${ }^{2}$, Thomas Sorensen ${ }^{2}$, John M. Kelly ${ }^{3}$, David. J. Cardin ${ }^{1}$ and Christine J. Cardin ${ }^{1 *}$

${ }^{1}$ Chemistry Department, University of Reading, Whiteknights, Reading, RG6 6AD, UK

${ }^{2}$ Diamond Light Source, Chilton, Didcot, Oxfordshire, OX11 0QX

${ }^{3}$ Trinity College, Dublin 2, Ireland

${ }^{4}$ School of Pharmacy, University of Reading, Whiteknights, Reading, RG6 6AD, UK

* To whom correspondence should be addressed. Tel: +44(0)1183788215; Email: c.j.cardin@ reading.ac.uk

\begin{abstract}
Hydration-dependent DNA deformation has been known since Rosalind Franklin recognised that the relative humidity of the sample had to be maintained to observe a single conformation in DNA fibre diffraction. We now report for the first time the crystal structure, at the atomic level, of a dehydrated form of a DNA duplex and demonstrate the reversible interconversion to the hydrated form at room temperature. This system, containing d(TCGGCGCCGA) in the presence of $\Lambda$-[Ru(TAP $\left.)_{2}(\mathrm{dppz})\right]^{2+}(\mathrm{TAP}=1,4,5,8$-tetraazaphenanthrene, dppz $=$ dipyridophenazine), undergoes a partial transition from an A/B hybrid to the A-DNA conformation, at $84-79 \%$ relative humidity. This is accompanied by an increase in kink at the central step from $22^{\circ}$ to $51^{\circ}$, with a large movement of the terminal bases forming the intercalation site. This transition is reversible on rehydration. Seven datasets, collected from one crystal at room temperature, show the consequences of dehydration at near-atomic resolution. This result highlights that crystals, traditionally thought of as static systems, are still dynamic and therefore can be the subject of further experimentation.

Introduction

It has been known, since the original DNA fibre diffraction experiments conducted by Franklin, with model building conducted by Watson and Crick, that relative humidity can induce changes in DNA structure $^{1}$. In fact, when Franklin collected her fibre diffraction data, she controlled the relative humidity inside the sample chamber using saturated salt solutions. This vital step maintained the humidity of the fibre, resulting in a single conformation rather than a mixture.
\end{abstract}


Since her original work, changes which induce a deformation, or change in conformation, of the DNA duplex have been studied intensively. These structural changes can be induced in a number of ways including chemical modification, ${ }^{2}$ covalent and non-covalent interactions with a ligand ${ }^{3,4}$ or protein ${ }^{5}$ and dehydration. ${ }^{6}$ A change in conformation, from the $\mathrm{B}$ to the A form, is observed in low humidity conditions and has been characterised by a number of methods including circular dichroism ${ }^{7,8}$ and other spectroscopic techniques. ${ }^{9}$

In contrast to the distortions induced by many small molecules, DNA kinking was first proposed as a necessary step required to enable the storage of DNA within the nucleus of a cell, ${ }^{10}$ making it more compact. The crystal structure of a nucleosome core particle ${ }^{11}$ showed how DNA can be bent into a superhelix around histone proteins. In the superhelix the single highest roll angle, for an AA/TT pair, is $27^{\circ}$ which is comparable to the $26^{\circ}$ roll angle induced by the binding of cis-platin to a GpG step in a DNA duplex. ${ }^{12}$ This is by no means the highest single-step kink which DNA can support whilst maintaining a Watson-Crick base pair. The structure of the TFAM-DNA (TFAM = mitochondrial transcription factor A) complex shows a $90^{\circ}$ bend in the DNA helix, across three steps, with the highest roll angle at a single step of $60^{\circ}$.

Previously, we reported the crystal structure of the DNA duplex of sequence d(TCGGCGCCGA) crystallized in the presence of $\Lambda$ - $\left[\operatorname{Ru}(\mathrm{TAP})_{2}(\mathrm{dppz})\right]^{2+},{ }^{13}$ with the complex and structure illustrated in figure 1 and 2a respectively. The complex is a part of a family of dppz-containing ruthenium compounds which have been the subject of intense research due to their interesting photophysical properties. ${ }^{14-17}$ The complex was found to intercalate, through the dppz group, into the $T_{1} C_{2}: G_{9} A_{10}$ step at both ends of the duplex. One TAP ligand (TAP1) however, semi-intercalated into the $\mathrm{G}_{3} \mathrm{G}_{4}: \mathrm{C}_{7} \mathrm{C}_{8}$ steps inducing a $51^{\circ}$ kink at each site, stabilised by a $\mathrm{Ba}^{2+}$ cation which is bound to the $\mathrm{N} 7$ position of $\mathrm{G}_{3}$ and bifurcated to both $\mathrm{O} 6$ and $N 7$ on $\mathrm{G}_{4}$. The central unbound $\mathrm{C}_{5} \mathrm{G}_{6}: \mathrm{C}_{5} \mathrm{G}_{6}$ step possessed a $22^{\circ}$ bend. Residue $\mathrm{A}_{10}$ flipped out and formed a reverse Watson-Crick base pair with $\mathrm{T}_{1}$ from a neighbouring duplex, thus cross linking all of the duplexes within the crystal.

Here we present the consequences of controlled dehydration on this system, as illustrated in figure $2 \mathrm{~b}$, using the $\mathrm{HC} 1 \mathrm{~b}$ humidity control device ${ }^{18}$ which replaces the cryojet on a macromolecular crystallography beamline and enables humidity control in real time. A reversible transition occurs at 84 $79 \%$ relative humidity, where a striking reversal in terminal base conformation occurs, with $\mathrm{T}_{1}$ now flipped out forming the reverse Watson-Crick base pair with $A_{10}$ from a neighbouring duplex, which requires the $A_{10}$ to flip in. A bend of $51^{\circ}$ has been induced at the central $C_{5} G_{6}: C_{5} G_{6}$ step and the unit cell volume has been reduced to $76 \%$ of its original volume. Additionally, the duplex also shows a partial 
transition from an A/B-hybrid to A-DNA conformation, which is the first such transition to be observed in the crystalline state. Unexpectedly, this transition is reversible on rehydration, to greater than $84 \%$ relative humidity, and seven crystal structures, charting this reversibility, were obtained from one crystal at room temperature, with one structure at near-atomic resolution. To our knowledge there is no record of such a reversible process in a nucleic acid crystal.

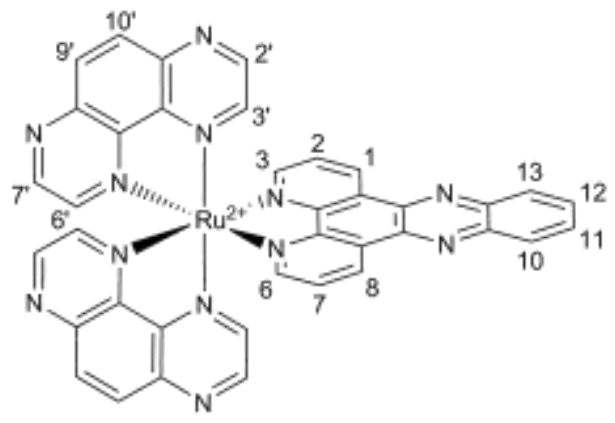

Figure 1: Diagram of $\Lambda-\left[\operatorname{Ru}(\mathrm{TAP})_{2}(\mathrm{dppz})\right]^{2+}$ 

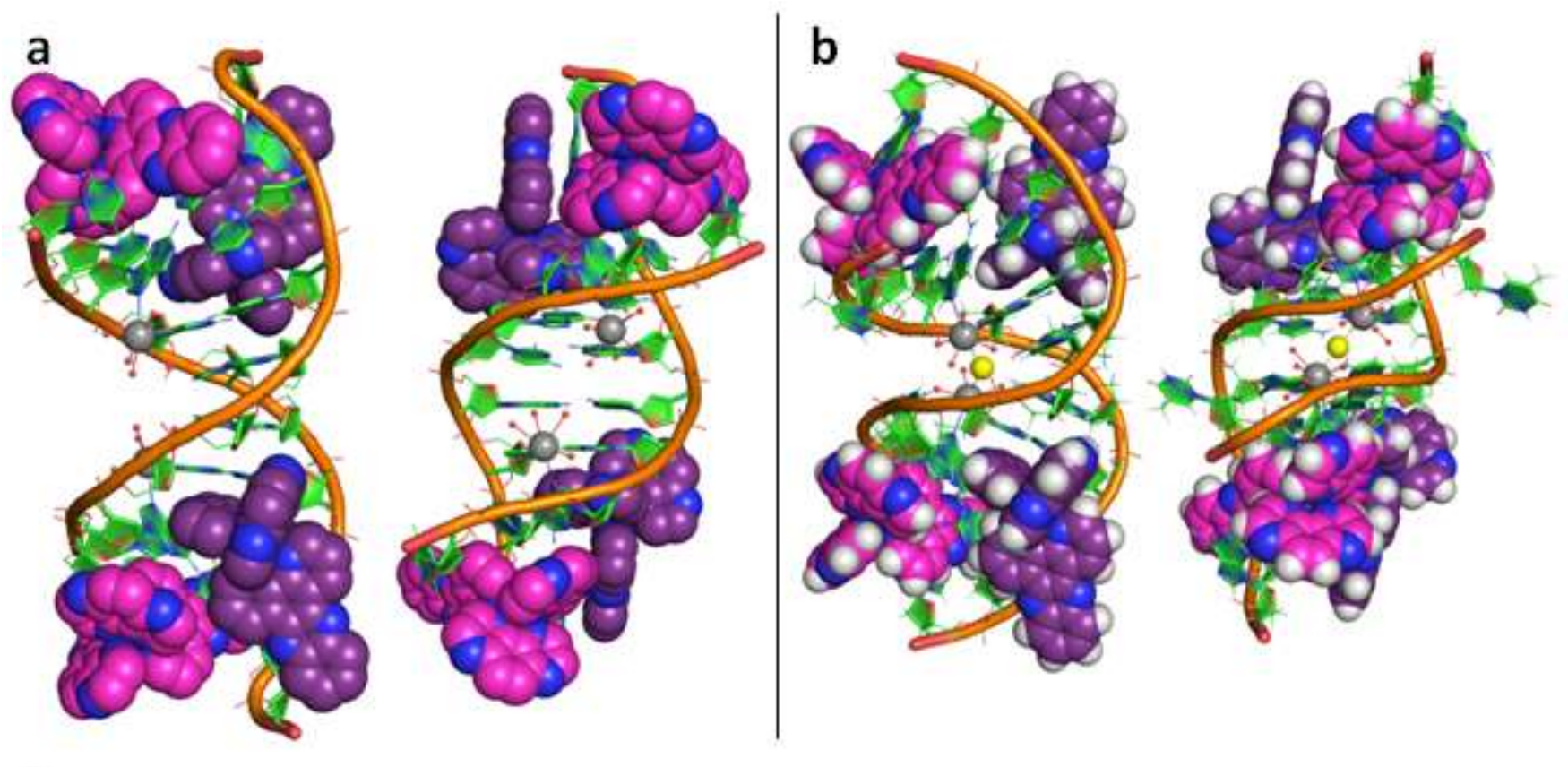

C

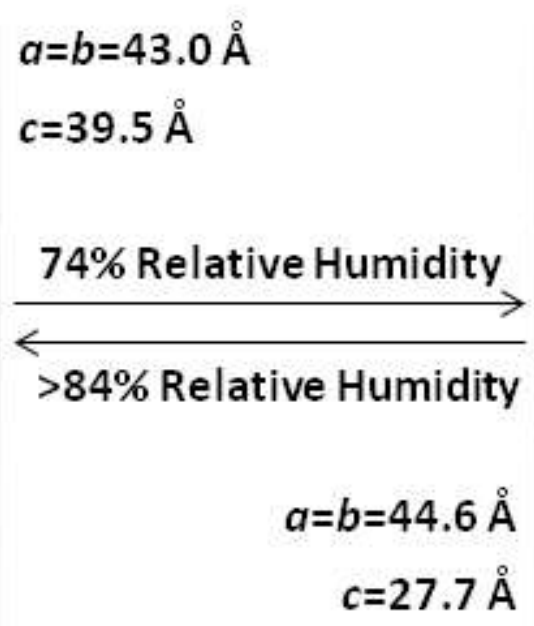

Figure 2: (a) Two views of the biological unit of structure 1 (99\% relative humidity, left) and $\mathbf{2}$ (74\% relative humidity, right). The left view in each panel is from the side of the duplex with the right view looking into the major groove. Note the narrowing of the major groove in the centre of the duplex and the chloride anion, which is bound to the $\mathrm{Ba}^{2+}$ in $\mathbf{2}$ but not in $\mathbf{1}$. Intercalating complexes have their carbon atoms coloured magenta with the carbons of semi-intercalating complexes in purple. Other atoms are coloured according to type with nitrogen in blue, oxygen in red, DNA carbon atoms in green, barium cation in silver, bound water molecules as red spheres and the chloride anion in yellow. The DNA backbone is drawn as a tube. (b) Two diffraction images collected from a crystal, at the same orientation, at $89 \%$ (left) and $74 \%$ (right) relative humidity. As the structure changes, so does the diffraction pattern. Note that the reflections extend to a higher resolution in the image collected from the dehydrated crystal. 


\section{Results}

Seven crystal structures were obtained from one crystal by varying both the beam position and relative humidity for each data collection. The structures are numbered 1-7 with key crystallographic statistics in table 1. Structures $\mathbf{1}, \mathbf{3}, \mathbf{5}$ and $\mathbf{7}$ are of the hydrated form with $\mathbf{2 , 4}$ and $\mathbf{6}$ as the dehydrated. For a structural comparison, only structures $\mathbf{1}$ and $\mathbf{2}$, the initial hydrated form and highest resolution dehydrated structure respectively, will be discussed. Subsequent structures in the same hydration state are isostructural apart from the number of ordered water molecules, as shown by the rmsd values in table 1 , performed using LSQKAB, comparing the DNA and ligand atoms in structures of the same hydration state. The crystals, when dehydrated, give remarkably different diffraction (figure $2 \mathrm{c}$ ) even though the spacegroup, $P 4_{3} 2_{1} 2$, is maintained. The solvent content is reduced from $66 \%$ in the hydrated form to $55 \%$ in the dehydrated. Initially it was difficult to collect data from a crystal which had undergone dehydration and rehydration multiple times, because of radiation damage occurring at room temperature. However, by taking a large crystal and changing the beam position for each dataset, the transition was repeated both on multiple crystals and multiple times on the same crystal.

Whilst gross structural features such as intercalation and semi-intercalation into the minor groove and barium cation coordination remain the same, the overall conformation of the DNA chain showed a transition further towards the A-DNA form. Full data collection and refinement statistics can be found in table S1 in the supplementary information. It should also be noted that when the crystal was dehydrated for the first time, to give structure $\mathbf{2}$, the data were of sufficient resolution to include hydrogen atoms, at calculated positions, within the model. This was not the case with the other six datasets.

\section{Intercalation Site}

Intercalation by the dppz of the complex into the $\mathrm{T}_{1} \mathrm{C}_{2}: \mathrm{G}_{9} \mathrm{~A}_{10}$ step is observed in both forms. In 1 $\mathrm{A}_{10}$ is flipped out, as illustrated in figure $3 \mathrm{a}$, and forms a reverse Watson-Crick base pair with $\mathrm{T}_{1}$ from a neighbouring symmetry equivalent duplex. Remarkably, in $\mathbf{2}$ this base flipping is reversed with $\mathrm{T}_{1}$ flipped out (figure 3a), forming the reverse Watson-Crick base pair with $\mathrm{A}_{10}$ from a neighbouring duplex, with $A_{10}$ flipped back in. In 1 the long axis of the dppz group is offset from the $\mathrm{G}_{9}-\mathrm{C}_{2}$ hydrogen bonds by $55^{\circ}$ which is increased to $65^{\circ}$ in $\mathbf{2}$. As a consequence of this reorientation, there is an increase in distance between the complex and DNA bases. The distance between $\mathrm{C7}^{\prime}$, on the TAP which is not semiintercalating, and $\mathrm{G}_{9}\left(\mathrm{NH}_{2}\right)$ is increased from $3.48 \AA$ to $4.08 \AA$ in structures $\mathbf{1}$ and $\mathbf{2}$ respectively, displayed in figure $\mathrm{S} 1$ in the supplementary information. Additionally, the distance between $\mathrm{C}^{\prime}$ and $\mathrm{G}_{3}\left(\mathrm{NH}_{2}\right)$ is also increased from $3.82 \AA$ to $4.40 \AA$, along with a similar increase to the $\mathrm{Ru}^{2+}$ which is given in table $\mathrm{S} 4$ in the supplementary information. This increase in distance in structure $\mathbf{2}$ is combined with slight 
pyramidalization of the $\mathrm{Ru}^{2+}$ coordinated dppz nitrogens which is not present in structure $\mathbf{1}$. As the complex is known to become strongly oxidising upon photoexcitation ${ }^{19-21}$, these structural changes might be expected to affect the rate of the forward electron transfer process. Equally the back reaction, which will determine the extent of permanent DNA damage, is expected to depend on the distance between the reduced TAP ligand in the metal complex and the transiently oxidised guanine.

Table 1 - Selected Data Collection and Refinement Statistics for 1-7

\begin{tabular}{|c|c|c|c|c|c|c|c|}
\hline Structure & 1 & 2 & 3 & 4 & 5 & 6 & 7 \\
\hline \multicolumn{8}{|l|}{ Cell dimensions } \\
\hline$a, c(\AA)$ & $42.9,39.5$ & $44.3,27.5$ & $42.9,39.4$ & $44.1,27.4$ & $43.1,39.4$ & $44.1,27.4$ & $43.1,39.3$ \\
\hline Resolution $(\AA)$ & $\begin{array}{c}29.09-1.50 \\
(1.54-1.50)^{*}\end{array}$ & $\begin{array}{l}31.32-1.18 \\
(1.21-1.18)\end{array}$ & $\begin{array}{l}30.39-1.60 \\
(1.64-1.60)\end{array}$ & $\begin{array}{l}31.25-1.41 \\
(1.45-1.41)\end{array}$ & $\begin{array}{l}30.48-1.80 \\
(1.85-1.80)\end{array}$ & $\begin{array}{l}27.49-1.45 \\
(1.19-1.45)\end{array}$ & $\begin{array}{c}30.5-2.07 \\
(2.12-2.07)\end{array}$ \\
\hline $\begin{array}{l}\text { Relative Humidity } \\
\qquad(\%)\end{array}$ & 97 & 74 & 97 & 74 & 97 & 74 & 97 \\
\hline Structural Form & Hydrated & Dehydrated & Hydrated & Dehydrated & Hydrated & Dehydrated & Hydrated \\
\hline $\begin{array}{l}\text { Unit Cell Volume } \\
\qquad\left(\AA^{3}\right)\end{array}$ & 72696 & 53968 & 72512 & 53287 & 73189 & 53287 & 73004 \\
\hline \multicolumn{8}{|c|}{ *Outer shell statistics given in parentheses } \\
\hline \multicolumn{8}{|l|}{ Refinement } \\
\hline No. Reflections & 5301 & 8525 & 4341 & 4994 & 3575 & 4913 & 2376 \\
\hline $\mathrm{R}_{\mathrm{work}} / \mathrm{R}_{\text {free }}$ & $0.13 / 0.15$ & $0.08 / 0.11$ & $0.14 / 0.17$ & $0.13 / 0.16$ & $0.14 / 0.18$ & $0.13 / 0.15$ & $0.15 / 0.19$ \\
\hline \multicolumn{8}{|l|}{ No. Atoms } \\
\hline DNA & 202 & 315 & 202 & 202 & 202 & 202 & 202 \\
\hline Complex & 51 & 73 & 51 & 51 & 51 & 51 & 51 \\
\hline Chloride & - & 1 & - & 1 & - & 1 & - \\
\hline Barium cation & 1 & 1 & 1 & 1 & 1 & 1 & 1 \\
\hline Water & 37 & 43 & 32 & 37 & 28 & 31 & 17 \\
\hline \multicolumn{8}{|l|}{ Average B factors } \\
\hline DNA & 29.20 & 20.02 & 29.63 & 20.18 & 32.59 & 20.85 & 39.91 \\
\hline Complex & 24.02 & 14.19 & 25.13 & 16.51 & 26.72 & 16.51 & 31.74 \\
\hline Chloride & - & 13.24 & - & 15.45 & - & 17.12 & - \\
\hline Barium cation & 24.12 & 12.24 & 24.85 & 16.56 & 27.61 & 15.69 & 34.40 \\
\hline Water & 45.14 & 37.17 & 42.04 & 33.03 & 41.25 & 31.55 & 42.80 \\
\hline $\begin{array}{l}\text { RMSD of all non- } \\
\text { water atoms, with } \\
\text { respect to } \mathbf{1} \text { or } \mathbf{2}(\AA)\end{array}$ & NA & NA & 0.058 & 0.173 & 0.072 & 0.074 & 0.134 \\
\hline PDB ID & 4LTF & 4LTG & 4LTH & 4LTI & 4LTJ & 4LTK & 4LTL \\
\hline
\end{tabular}


a

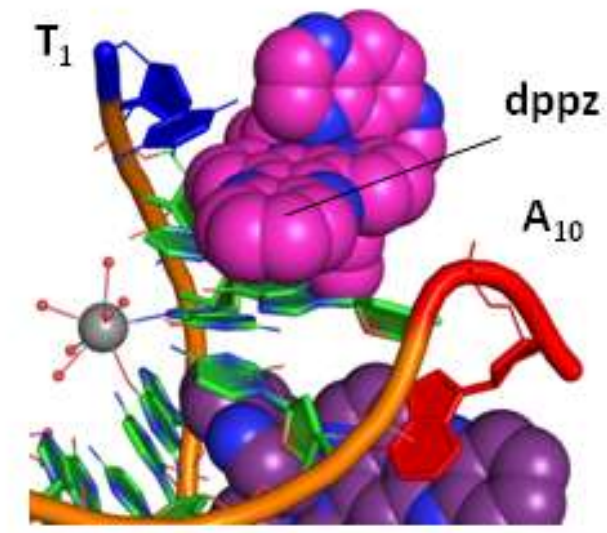

b
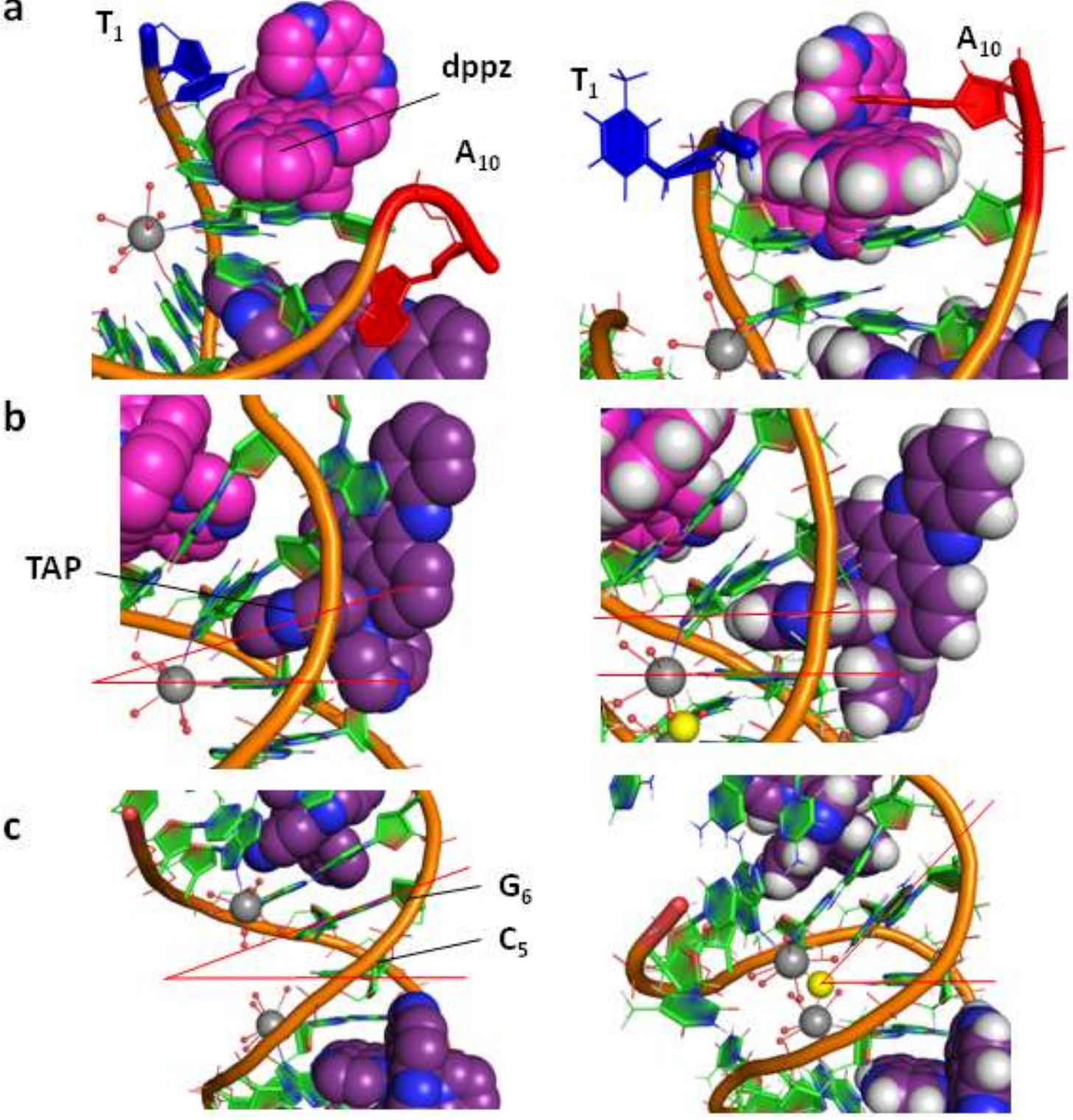

Figure 3: (a) In 1 (hydrated) the $T_{1}$ (blue) is stacked on top of the dppz with $A_{10}$ (red) flipped out (left). However, in the dehydrated form this is reversed so that $T_{1}$ is flipped out and $A_{10}$ is flipped back in. (b) In 1 a TAP lies between the $\mathrm{G}_{3} \mathrm{C}_{7}$ and $\mathrm{G}_{4} \mathrm{C}_{6}$ base pairs. The angle between the plane of the TAP and $\mathrm{G}_{4} \mathrm{C}_{6}$ base pair, indicated by red lines, is approximately $20^{\circ}$. This is reduced to $<10^{\circ}$ in structure 2 and the TAP no longer stacks onto the $\mathrm{G}_{3} \mathrm{C}_{7}$ base pair. (c) The roll angle at the central $\mathrm{C}_{5} \mathrm{G}_{6}: \mathrm{C}_{5} \mathrm{G}_{6}$ base pair is $23^{\circ}$ but, when dehydrated to give 2 , is increased to $51^{\circ}$, as indicated by red lines. Also note the barium cations, drawn in silver, have moved closer together in $\mathbf{2}$ and are bridged by a chloride anion (yellow). Unless otherwise specified carbons from the intercalating complexes are in magenta with those form the semiintercalating compound in purple. All other atoms are coloured according to element with carbon in green, nitrogen in blue, oxygen in red, phosphorus in orange, hydrogen in white and bound water molecules as red spheres. 


\section{Semi-intercalation Site and Barium Coordination Environment}

One TAP group (TAP1) from the complex semi-intercalates into the $\mathrm{G}_{3} \mathrm{G}_{4}: \mathrm{C}_{7} \mathrm{C}_{8}$ base pairs, inducing a kink in the duplex. The size of this kink is $51^{\circ}$ in $\mathbf{1}$ but is reduced to $48^{\circ}$ in 2 . The kink is stabilised by a $\mathrm{Ba}^{2+}$ cation which is bound to $\mathrm{G}_{3}(\mathrm{~N} 7)$ and bifurcated to $\mathrm{G}_{4}$. In $\mathbf{1}$ the TAP is almost equidistant from $\mathrm{G}_{3}: \mathrm{C}_{8}$ and $\mathrm{G}_{4}: \mathrm{C}_{7}$ but, when dehydrated to give 2 , the TAP group stacks fully onto $\mathrm{G}_{4}: \mathrm{C}_{7}$, as illustrated in figure $3 \mathrm{~b}$. The barium cations at these steps are $9.3 \AA$ apart in $\mathbf{1}$, with a full coordination shell of six water molecules, but move closer to $5.9 \AA$ when dehydrated. This is attributed to the increased kink at the central step, which will be discussed later. As a consequence of this movement there is no longer space to accommodate a full coordination shell of water molecules around the cations, and one water molecule from each barium coordination sphere has been replaced by a bridging chloride anion (figure 3c). The assignment of a chloride anion was based on a typical Ba-Cl bond distance of $3.2 \AA^{22}$ and a $7 \sigma$ peak in the $\mathrm{F}_{\mathrm{o}}-\mathrm{F}_{\mathrm{c}}$ difference map when the peak is assigned as water. The $\mathrm{Cl}^{-}$comes from the solvent channels, which would contain $\mathrm{NaCl}$ from the crystallization solution, and are able to move into the structure as the data are collected at room temperature.

\section{Central Step}

In both forms the central $\mathrm{C}_{5} \mathrm{G}_{6}: \mathrm{C}_{5}: \mathrm{G}_{6}$ step is unbound. In 1 the roll angle for this step is $23^{\circ}$ but, when dehydrated, this increases to $51^{\circ}$ (figure $3 \mathrm{c}$ ) which is almost identical to the bend induced by semiintercalation of the TAP1 group, although there is no ligand binding at this step. This kink is believed to be stabilised by interstrand water mediated hydrogen bonds, which are discussed later.

\section{Conformational Analysis}

The sugar pucker analysis shows that structure $\mathbf{1}$ possesses a conformation which is a hybrid between the B and A-DNA form. Five nucleotides possess a B-DNA pucker with the other five adopting an A-DNA conformation. However, after dehydration, the helix has adopted a form closer to that of ADNA, with eight out of ten bases possessing the typical A-DNA C3'-endo/C4'-exo pucker, and two guanines, $\mathrm{G}_{4}$ and $\mathrm{G}_{6}$, retaining the $\mathrm{C}^{2}$ '-endo pucker of $\mathrm{B}-\mathrm{DNA}$. This could be because by preserving this pucker the stacking between $\mathrm{G}_{4}$ and the complex is maximised. However, for $\mathrm{G}_{6}$, the retention of the sugar as $\mathrm{C} 2^{\text {' }}$-endo maximises the stacking onto $\mathrm{C}_{7}$, as a transition to $\mathrm{C}^{2}$ '-endo could result in a translation of the base towards the major groove. Details of the sugar pucker analysis can be found in table 2. All calculations were performed using W3DNA ${ }^{23}$.

The highly detailed study, reported by Shing Ho et al, reports a transition from B to A-DNA observed in 13 different crystal structures of d(GGCGCC $)^{24}$. Whilst this sequence is the same as the core 
of the DNA used in this study, $d\left(\mathrm{~T}_{1} \mathrm{C}_{2} \mathrm{G}_{3} \mathrm{G}_{4} \mathrm{C}_{5} \mathrm{G}_{6} \mathrm{C}_{7} \mathrm{C}_{8} \mathrm{G}_{9} \mathrm{~A}_{10}\right)$ with the core highlighted in red, comparison with this work is difficult. The reason is that at the $\mathrm{G}_{3} \mathrm{G}_{4} \mathrm{C}_{7} \mathrm{C}_{8}$ and $\mathrm{C}_{7} \mathrm{C}_{8}: \mathrm{G}_{3} \mathrm{G}_{4}$ steps a TAP group is semiintercalated into the DNA. In addition to this, in the dehydrated form, the DNA is kinked at the central $\mathrm{C}_{5} \mathrm{G}_{6} \mathrm{C}_{5} \mathrm{G}_{6}$ site. A comparison of the distribution of $\chi$ and $\delta$ torsion angles for this core is displayed in figure S2 and table S2 in the supplementary information, and shows that both $\mathbf{1}$ and $\mathbf{2}$ display an approximately equal set of these two torsion angles. The rise distance and twist angle at each step have also been calculated and can be found in table S3 in the supplementary information. These show that at semi-intercalated sites the rise distance is increased to approximately $5 \AA$, compared to the $3.4 \AA$ rise for B-DNA, but this is combined with a reduction at non-interacting steps, from $3.24 \AA$ in $\mathbf{1}$ to $2.97 \AA$ in 2 . However, there is also an increase in rise distance at the central $\mathrm{C}_{5} \mathrm{G}_{6}: \mathrm{C}_{5} \mathrm{G}_{6}$ step, from $3.56 \AA$ in $\mathbf{1}$ to 4.78

$\AA$ in 2, which is attributed to the formation of a kink. The DNA is unwound at the semi-intercalated sites, to $15^{\circ}$, but is more tightly wound at the $\mathrm{G}_{4} \mathrm{C}_{5}$ and $\mathrm{G}_{6} \mathrm{C}_{7}$ steps to $38^{\circ}$. The twist at the central step is lower in $\mathbf{2}\left(16^{\circ}\right)$ than in $\mathbf{1}\left(26^{\circ}\right)$ which is again attributed to the kink.

Therefore, for this work, the sugar pucker has been chosen as the most appropriate criterion as both intercalation and semi-intercalation of a ligand will limit, or bias, the conformational flexibility of the bases around the interaction site. For example, intercalation by a planar ligand will limit the flexibility of a base to rotate around $\chi$ as if the base rotates it would clash with the intercalating group. In addition to this the rise distance at the intercalation site would be increased and, depending on the identity of the group, the twist could either be increased ${ }^{25}$ or decreased ${ }^{26}$ compared to B-DNA. $^{2}$

\section{Water Structure}

In structure 1 (hydrated form) the water structure is largely unremarkable. A majority of the molecules are located in the major groove, as the minor groove is largely blocked by the four interacting Ruthenium complexes. Hydrogen bonding between water molecules and the phosphate backbone is common in the structure. The $\mathrm{Ba}^{2+}$ cations possess a coordination shell with six water molecules. A hydrogen bond is present between $\mathrm{HOH} 225$, which is coordinated to the $\mathrm{Ba}^{2+}$ cation, and $\mathrm{G}_{4}(\mathrm{O} 6)$ which is illustrated in figure $4 \mathrm{a}$. This is the only example of an interstrand cross-link in the structure, and is mediated by a single water molecule.

However, in the transformation to structure 2, five water mediated interstrand crosslinks are formed. These occur either by (1) forming a hydrogen bonded bridge through a single water molecule between two phosphate groups on opposing strands or (2) via a water molecule coordinated to the $\mathrm{Ba}^{2+}$ cation on one strand and a phosphate group on the other, as illustrated in figure $4 \mathrm{~b}$. This hydrogen bonding network could explain why the dehydrated form diffracts to a higher resolution, as an increase in 
intermolecular bonding would increase the order of the system. Whilst a majority of the water molecules are found in the major groove, or major groove side of the duplex, there is a slight increase in the number found in the minor groove. This could be because the kink at the central step opens up the minor groove side of the DNA allowing hydrogen bond formation with groups on the floor of the groove.

The formation of the bridging network is only possible because the phosphate backbone of the two strands approach so closely to each other. The separation between $G_{3}(P)$ on one strand and $G_{4}(P)$ on the other is $7.76 \AA$ but the $\mathrm{G}_{3}(\mathrm{P})-\mathrm{G}_{3}(\mathrm{P})$ distance is even shorter at $6.09 \AA$, much smaller than the major groove separation observed, in multiple A-DNA crystal structures, of approximately $10 \AA^{27}$. This is attributed to the combination of the A-DNA conformation and the inducement of an increased kink, bending the helix towards the major groove, at the central step.

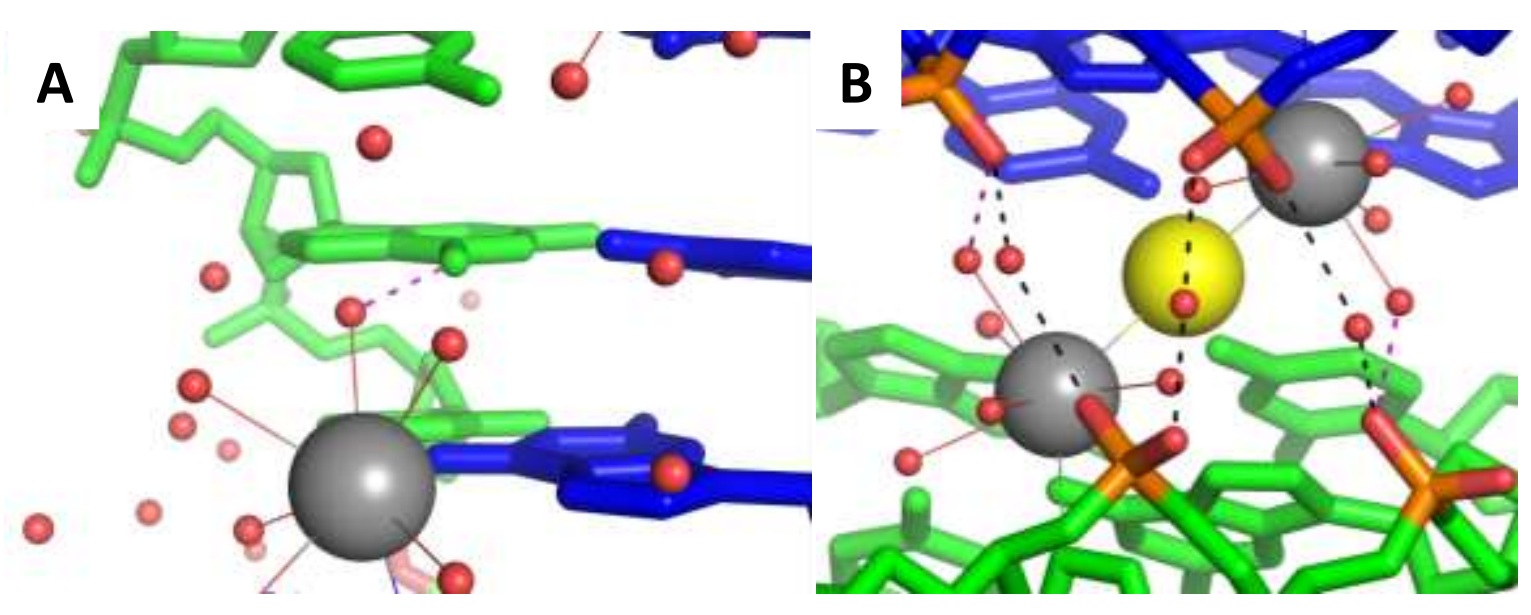

Figure 4: Water mediated interstrand crosslinking, in the major groove, in structure 1 (left) and 2 (right). The only example of this in structure $\mathbf{1}$ is where a water coordinated to the $\mathrm{Ba}^{2+}$ forms a hydrogen bond with $\mathrm{G}_{6}(\mathrm{O} 6)$ from the opposing strand. However in structure 2 there are three water molecules which form bridging hydrogen bonds between $\mathrm{G}_{3}(\mathrm{OP} 1), \mathrm{G}_{3}(\mathrm{OP} 2)$ and $\mathrm{G}_{4}(\mathrm{OP} 2)$ on opposing strands. Additionally two hydrogen bonds are formed between waters coordinated to the $\mathrm{Ba}^{2+}$ and $\mathrm{G}_{4}(\mathrm{OP} 2)$. The two opposing DNA strands are illustrated in green and blue. Hydrogen-bonded phosphate groups are coloured according to type with oxygen in red and phosphorus in orange. Other atoms are coloured according to type with the $\mathrm{Ba}^{2+}$ cation displayed in grey, chloride anion in yellow and water molecules as red spheres. Interstrand hydrogen bonds are indicated by dashed lines, in black to indicate $(\mathrm{P}) \mathrm{O}-\mathrm{HOH}-$ $\mathrm{O}(\mathrm{P})$ links and magenta to highlight $\mathrm{Ba}^{2+}-\mathrm{HOH}-\mathrm{O}$ interactions. 
Table 2: Conformational analysis for structures $\mathbf{1}$ and 2. In all cases the parameter before the forward slash is for structure $\mathbf{1}$ with structure $\mathbf{2}$ given after.

\begin{tabular}{cccc}
\hline Base & Phase angle of pseudorotation & $\begin{array}{c}\text { Assigned Sugar } \\
\text { Pucker }\end{array}$ & $\begin{array}{c}\text { Closest DNA } \\
\text { Conformation }\end{array}$ \\
\hline $\mathrm{T}$ & $34.7 / 30.1$ & $\mathrm{C} 3$ '-endo/C3'-endo & $\mathrm{A} / \mathrm{A}$ \\
$\mathrm{C}$ & $36.1 / 17.2$ & $\mathrm{C} 3$ '-endo/C3'-endo & $\mathrm{A} / \mathrm{A}$ \\
$\mathrm{G}$ & $18.2 / 15.8$ & $\mathrm{C} 3$ '-endo/C3'-endo & $\mathrm{A} / \mathrm{A}$ \\
$\mathrm{G}$ & $161 / 177.1$ & $\mathrm{C} 2$ '-endo/C2'-endo & $\mathrm{B} / \mathrm{B}$ \\
$\mathrm{C}$ & $27.7 / 34.5$ & $\mathrm{C} 3$ '-endo/C3'-endo & $\mathrm{A} / \mathrm{A}$ \\
$\mathrm{G}$ & $155.7 / 173$ & $\mathrm{C} 2$ '-endo/C2'-endo & $\mathrm{B} / \mathrm{B}$ \\
$\mathrm{C}$ & $53.6 / 47.2$ & $\mathrm{C} 4$ '-exo/C4'-exo & $\mathrm{A} / \mathrm{A}$ \\
$\mathrm{C}$ & $88.7 / 30.3$ & O4'-endo/C3'-endo & $\mathrm{B} / \mathrm{A}$ \\
$\mathrm{G}$ & $156.9 / 8.0$ & $\mathrm{C} 2$ '-endo/C3'-endo & $\mathrm{B} / \mathrm{A}$ \\
$\mathrm{A}$ & $162.7 / 14.1$ & $\mathrm{C} 2$ '-endo/C3'-endo & $\mathrm{B} / \mathrm{A}$
\end{tabular}

\section{Reversibility}

What is striking, and quite unforeseen, about this study is that the transition, between the hydrated and dehydrated forms, is reversible when the relative humidity around the sample is increased. This is despite a large difference in the length of the $c$ axis, which is $39 \AA$ in the hydrated form but is reduced to $27 \AA$ when dehydrated. The unit cell volume for the hydrated form is $72,696 \AA^{3}$ and the volume of the dehydrated form is $53,968 \AA^{3}$ so, after dehydration, the unit cell is $74 \%$ of its original volume. The solvent content of the hydrated and dehydrated form is $66 \%$ and $55 \%$ respectively, calculated using UCSF Chimera, ${ }^{28}$ showing a drop in solvent content within the crystal. When water is removed the solvent channels contract in size, as illustrated in figure 5 and a $51^{\circ}$ kink is induced in the central step, as discussed above. In addition to this the dehydrated form, in all cases, possesses lower average B-factors for the DNA and exhibits higher resolution diffraction than the preceding or subsequent hydrated form, as illustrated in figure S3 in the supplementary information. In addition to this there are more ordered water molecules in the dehydrated structures compared to the hydrated, despite the latter possessing a higher solvent content. 
a

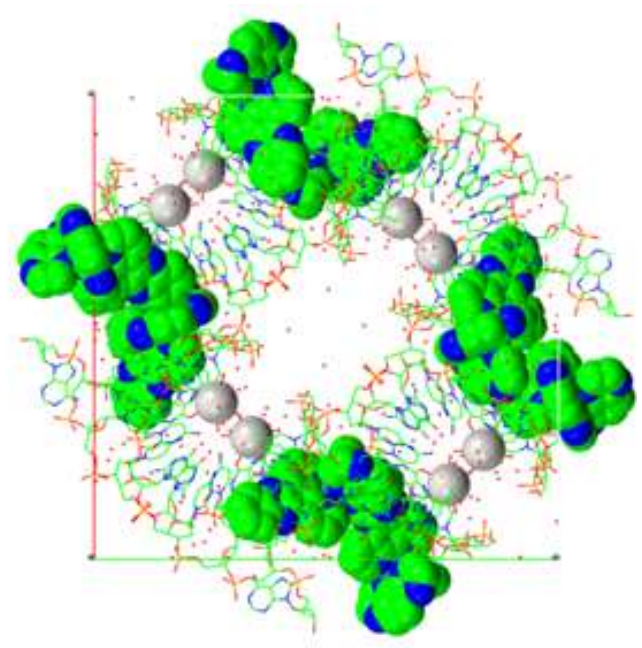

b

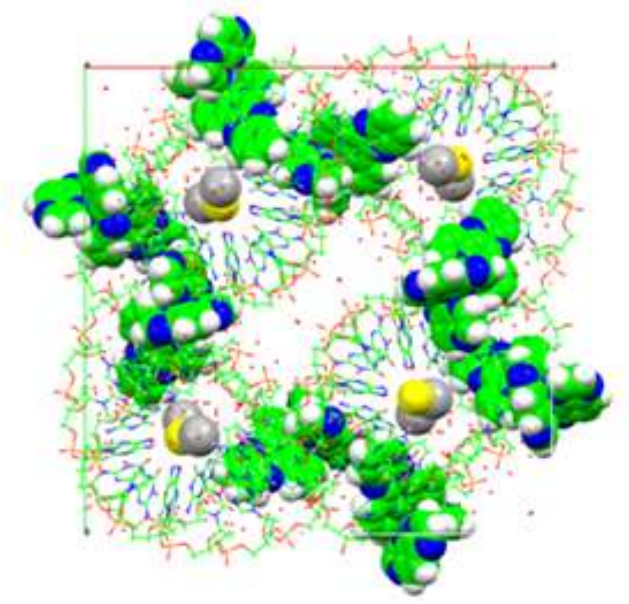

Figure 5: Packing diagrams, in space group $P 4_{3} 2{ }_{1} 2$, viewed down the $c$ axis, for (a) structure 1 and (b) 2. Note the contraction in the central solvent channel in structure $\mathbf{2}$ (dehydrated) compared to $\mathbf{1}$ (hydrated). Atoms are coloured according to type with carbon in green, oxygen in red, nitrogen in blue, phosphorus in orange, hydrogen in white, $\mathrm{Ba}^{2+}$ in silver and chloride in yellow. The $\Lambda-\left[\mathrm{Ru}(\mathrm{TAP})_{2}(\mathrm{dppz})\right]^{2+}, \mathrm{Ba}^{2+}$ and $\mathrm{Cl}^{-}$ are displayed as a space filling model. 


\section{Conclusions}

Previously it has been found that at a low relative humidity it is possible to obtain multiple DNA conformations, including the $\mathrm{A}^{29}$ and $\mathrm{Z}-\mathrm{DNA}^{30}$ forms, using a variety of techniques. Yet, whilst the $\mathrm{A}$ and B-DNA forms have been crystallized individually, ${ }^{31,32}$ there have been no reports of inducing a full, or partial, transition between the two in a single crystal. Dehydration of DNA crystals has previously been reported but only resulted in an increase in diffraction resolution and not accompanied by a transition between DNA forms ${ }^{33}$ possibly due to the presence of a minor groove binding agent which would restrict conformational changes.

Whilst the transition between $\mathbf{1}$ and $\mathbf{2}$ is not a full transformation, it does represent a partial conformational shift, from an A/B hybrid to an $80 \%$ A-DNA conformation. This was an unexpected consequence of the dehydration, which is traditionally used to increase diffraction quality in poorly diffracting crystals. ${ }^{34}$ In fact, an increase in order in the system when performing the dehydration systematically was observed. The ability to induce the transition between the hydrated and dehydrated form, and then reverse it again on demand, was not expected and is made even more unusual as it was accompanied by a large structural change.

The induction of a kink is particularly interesting as it highlights the inherent flexibility of the DNA duplex, even in the crystalline state. This flexibility is exploited by DNA-mismatch repair proteins, which travel along the helical axis of the duplex searching for regions of increased flexibility, compared to well matched base pairs, which indicates the presence of a mismatch. ${ }^{35}$ The question of why a single kink is induced instead of a bend is an interesting one. Instead of completely destacking the central $\mathrm{C}_{5} \mathrm{G}_{6}: \mathrm{C}_{5} \mathrm{G}_{6}$ base pair, the $\mathrm{G}_{4} \mathrm{C}_{5}: \mathrm{G}_{6} \mathrm{C}_{7}$ and $\mathrm{G}_{6} \mathrm{C}_{7}: \mathrm{G}_{4} \mathrm{C}_{5}$ steps could have been partially destacked, along with the central step, forming a less sharp bend across the three base pairs. A GC base pair stack is more stable than a CG stack, stabilising the duplex by $-2.70 \mathrm{kcal} / \mathrm{mol}^{-1}$ and $-1.44 \mathrm{kcal} / \mathrm{mol}^{-1}$ respectively, ${ }^{36}$ and therefore it is more favourable to destack the central step rather than partially destack all three pairs.

In terms of biological relevance, the hydrated form could be said to be more representative as the dehydrated structure can only be formed when the crystal is dehydrated to a relative humidity which is comparable to that of a $6.3 \mathrm{M} \mathrm{NaCl}$ solution. ${ }^{37}$ This is difficult to compare to the solvent environment in vivo as information about the solvent content of organelles, in a particular cell type, is limited. One study has reported that the water content of organelles within HeLa cells is $65-80 \%{ }^{38}$ but, as the solvent content of crystals is a direct consequence of crystal packing, this does not enable comparison with known crystal structures. Relative humidity may be a more suitable metric as it is demonstrated here, and with previously reported systems, that structural transitions can be induced by dehydration. ${ }^{39}$ 
The relative humidity at which a structure exists should be reported to ensure that it is possible for this form to exist in vivo. What should be highlighted is that, in our case, an analysis of the dehydrated form would have led to the conclusion that intercalation at the central step of the decamer was impossible, due to the large kink. Instead, we have previously reported the symmetrical intercalation of an additional ruthenium complex at this central step, using a slightly different sequence. ${ }^{25}$

This study reports the consequences to DNA structure which are observed when the DNA is both dehydrated and kinked simultaneously and reveals an interesting new hydrogen-bonding motif. When DNA is kinked, for example by cis-platin, the interstrand phosphate distance in the major groove can be reduced to approximately $10 \AA^{3,12}$, similar to the $9 \AA$ separation observed in A-DNA ${ }^{27}$. However, in both cases, individual water molecules are unable to form a $\mathrm{P}(\mathrm{O})-\mathrm{HOH}-(\mathrm{O}) \mathrm{P}$ bridge as the distance is too great. In our study we observe an intermolecular P-P distance as low as $6.1 \AA$, enabling single water molecules to form $\mathrm{H}$-bonded bridges between the phosphate oxygen atoms. The extra hydrogen bonds from both the bridging water and $\mathrm{Ba}^{2+}$ coordinated water would stabilise the new form, and is presumably one reason why this dehydrated conformation is stable in the crystal and is formed uniformly.

This new binding motif has implications for both molecular engineering and DNA self assembly. Water content has been found to affect the formation of twists in a cationic amphiphile consisting of pyridinium and a long chain glutamide $(\mathrm{PULG})^{40}$. It was reported that altering the amount of water changed the magnitude of the uniform twist observed in a single PULG strand. In addition to this, gelation was only able to occur in the presence of water, and not organic solvents alone, suggesting that one key factor in the formation of the gel was the occurrence of water mediated intermolecular hydrogen bonds between the polar groups. Our system also changes structure as a function of relative humidity and therefore is an example of a hydration sensitive supramolecular switch. It has also been shown that DNA intercalators, such as ethidium, can promote the formation of error-free self-assembled DNA nanostructures $^{41}$ and therefore one must consider whether the introduction of a semi-intercalator could promote a kinked structure. If assembly were performed in a low-humidity environment, in the presence of a semi-intercalator, then it may be possible that water mediated interstrand crosslinks could form, in a similar manner to those observed here, affecting the final structure. It should also be noted the crystals reduce in size, on the micron scale, when dehydrated and therefore could be used to activate a mechanical switch at a particular relative humidity.

This result highlights that crystals, traditionally thought of as static systems, can still be dynamic at room temperature and can therefore be the subject of further experimentation after growth. Now that this crystal system has been established as robust, the possibility of exploring the reactivity of the 
complex within the crystalline state will be explored because, as commented on above, the hydrationinduced changes in the interaction of the metal complex might have a significant effect on the photophysical properties of the complex.

\section{Methods}

\section{Crystallization}

The oligonuclotide d(TCGGCGCCGA) was purchased from ATDBio as a solid purified by double-HPLC. $\Lambda$-[Ru(TAP) $\left.)_{2}(\mathrm{dppz})\right] .2 \mathrm{Cl}$ was synthesised according to literature methods. ${ }^{13,19}$ Crystals containing the nucleotide and the complex $\Lambda-\left[\operatorname{Ru}(\mathrm{TAP})_{2}(\mathrm{dppz})\right] .2 \mathrm{Cl}$ were grown using vapour diffusion from sitting drops at $18^{\circ} \mathrm{C}$. The drops contained $1 \mu \mathrm{l}$ of $2 \mathrm{mM}$ oligonucleotide, $1 \mu 1$ of $4 \mathrm{mM} \mathrm{rac-}$ $\left[\mathrm{Ru}(\mathrm{TAP})_{2}(\mathrm{dppz})\right] \mathrm{Cl}_{2}$ and $6 \mu \mathrm{l}$ of the following solution; $10 \%$ (vol/vol) MPD, $40 \mathrm{mM}$ sodium cacodylate (pH 6.0), $12 \mathrm{mM}$ spermine tetra- $\mathrm{HCl}, 80 \mathrm{mM}$ sodium chloride and $20 \mathrm{mM}$ barium chloride. The drop was equilibrated against $1 \mathrm{ml}$ of $35 \%$ (vol/vol) MPD and reddish-yellow rhombohedra appeared after approximately one week. It should be noted that individual crystals possessing the hydrated or dehydrated unit cells were found in the same crystallization drop.

\section{Data Collection and Refinement}

All seven data sets were collected from a single crystal, of approximate dimensions $150 \mathrm{x} 180 \mathrm{x}$ 100um with a $0.3 \mathrm{~s}$ exposure time on beam line I02 at Diamond Light Source Ltd with radiation of wavelength $0.8266 \AA$ A. Data were collected at $295 \mathrm{~K}$. A total of $90^{\circ}$ of data were collected in 90 images with a $1^{\circ}$ oscillation angle. Each dataset was collected from a separate volume of the crystal to minimise the effects of radiation damage. The data were integrated with $x i a 2^{42}$ with $\mathrm{XDS}^{43}$ and processed using SCALA $^{44}$. The structures were solved by molecular replacement using Phaser ${ }^{45}$ with $\mathbf{3 Q R N}$ as the starting model for the hydrated data sets and 3S80, a low resolution structure solved from data collected on the Gemini-S-Ultra single crystal diffractometer in the Chemical Analysis Facility at the University of Reading, for the dehydrated data sets. The models were refined using REFMAC5 ${ }^{46}$ after being updated with $\mathrm{Coot}^{47}$. The CCP4 suite was used throughout ${ }^{48}$. Five percent of reflections were reserved for the $\mathrm{R}_{\text {free }}$ set. All models were deposited in the Protein Data Bank with the following ID's: 4LTF, 4LTG, 4LTH, 4LTI, 4LTJ, 4LTK and 4LTL. Selected statistics can be found in table 1 with full data collection and refinement statistics in table $\mathrm{S} 1$ in the Supplementary Information. 


\section{Dehydration}

A drop $(<1 \mu 1)$ of the crystal mother liquor was mounted on a Micromesh from MiteGen and placed on the goniometer of beamline I02 at Diamond Light Source Ltd. The initial relative humidity (RH) of the mother liquor was $99 \%$ and was found according to literature methods. ${ }^{39}$ The crystal was then mounted, on the same Micromesh, and two minutes allowed for the crystal humidity to equilibrate. Next, three diffraction frames $45^{\circ}$ apart were taken to establish a baseline for both the unit cell dimensions and diffraction quality. Automated processing available on the beamline using EDNA $^{49}$ was used throughout to index the diffraction frames.

Next, a crystal was dehydrated at a rate of $2 \% \mathrm{RH}$ per minute, with three frames of data collected after each two percent change. A drop in diffraction quality was observed at $84 \%$ relative humidity and the diffraction spots became poorly defined. Diffraction quality then increased at $74 \%$ relative humidity, associated with a change in unit cell dimensions. The relative humidity was then increased to $99 \%$, at $2 \%$ per minute, and three frames of data, $45^{\circ}$ apart, were taken. This gave an increase in unit cell dimensions

Another crystal was mounted on a Micromesh from MiTeGen and was equilibrated to $97 \%$ relative humidity, with the mother liquor humidity found using the same method. The crystal was repeatedly dehydrated and rehydrated to give seven datasets which in turn yielded seven structures (4LTF, 4LTG, 4LTH, 4LTI, 4LTJ, 4LTK and 4LTL in the Protein Data Bank). The HC1b humidity control device was used throughout to control the relative humidity at the sample position. This device replaces the cryojet and allows for monitoring of the crystal by diffraction whilst changing relative humidity. Figure S4, showing the appearance of the crystal before and after dehydration, is given in the supplementary information.

\section{Associated Information}

Full data collection and refinement statistics, along with figure S5, showing $\mathbf{1}$ and $\mathbf{2}$ superimposed, are available in the supplementary information.

\section{Author Contributions}

J.P.H wrote the paper with input from all other authors. J.P.H and J.S-W carried out the experiments, using materials synthesised by C.A, C.H.Q, K.O'S, J.M.K and D.J.C. J.P.H, C.J.C and J.S-W designed the experiment. J.A.B, T.S and G.W assisted with analysis of the results and useful discussions. 


\section{Corresponding Author}

c.j.cardin@rdg.ac.uk

\section{Competing Financial Interests}

The authors declare no competing financial interest

\section{Acknowledgements}

J.P.H is funded by Diamond Light Source and the University of Reading. We acknowledge additional financial support from the Royal Society, the Royal Irish Academy and the Science Foundation Ireland (grant 06/RF/CHP035). This work was supported by BBSRC grant BB/K019279/1 awarded to C.J.C, J.A.B and T.S. 


\section{References}

(1) Klug, A. J. Mol. Biol. 2004, 335, 3.

(2) Jensen, G. A.; Singh, S. K.; Kumar, R.; Wengel, J.; Jacobsen, J. P. J. Chem. Soc. Perk. T. 2. 2001, 1224.

(3) Takahara, P. M.; Frederick, C. A.; Lippard, S. J. J. Am. Chem. Soc. 1996, 118, 12309.

(4) Song, H.; Kaiser, J. T.; Barton, J. K. Nat. Chem. 2012, 4, 615.

(5) Ohndorf, U. M.; Rould, M. A.; He, Q.; Pabo, C. O.; Lippard, S. J. Nature 1999, 399, 708.

(6) Gray, D. M.; Edmondson, S. P.; Lang, D.; Vaughan, M.; Nave, C. Nucleic Acids Res. 1979, 6, 2089.

(7) Hanlon, S.; Brudno, S.; Wu, T. T.; Wolf, B. Biochemistry 1975, 14, 1648.

(8) Wolf, B.; Hanlon, S. Biochemistry 1975, 14, 1661.

(9) Kagawa, K.; Howell, M. L.; Tseng, K.; Ho, P. S. Nucleic Acids Res. 1993, 21, 5978.

(10) Crick, F. H. C.; Klug, A. Nature 1975, 255, 530.

(11) Luger, K.; Mäder, A. W.; Richmond, R. K.; Sargent, D. F.; Richmond, T. J. Nature 1997, $389,251$.

(12) Todd, R. C.; Lippard, S. J. J. Inorg. Biochem. 2010, 104, 902.

(13) Hall, J. P.; O’Sullivan, K.; Naseer, A.; Smith, J. A.; Kelly, J. M.; Cardin, C. J. Proc. Natl. Acad. Sci. USA. 2011, 108, 17610.

(14) Kelly, J. M.; McConnell, D. J.; OhUigin, C.; Tossi, A. B.; Mesmaeker, A. K.-D.; Masschelein, A.; Nasielski, J. J. Chem. Soc. Chem. Comm. 1987, 24, 1821.

(15) Vos, J. G.; Kelly, J. M. Dalton. T. 2006, 4869.

(16) Gill, M. R.; Thomas, J. A. Chem. Soc. Rev. 2012, 41, 3179.

(17) Friedman, A. E.; Chambron, J. C.; Sauvage, J. P.; Turro, N. J.; Barton, J. K. J. Am. Chem. Soc. 1990, 112, 4960.

(18) Sanchez-Weatherby, J.; Bowler, M. W.; Huet, J.; Gobbo, A.; Felisaz, F.; Lavault, B.; Moya, R.; Kadlec, J.; Ravelli, R. B. G.; Cipriani, F. Acta. Crystallogr. 2009, D65, 1237. 
(19) Ortmans, I.; Elias, B.; Kelly, J. M.; Moucheron, C.; Kirsch-DeMesmaeker, A. Dalt. Trans. 2004, 668.

(20) Elias, B.; Kirsch-De Mesmaeker, A. Coord. Chem. Rev. 2006, 250, 1627.

(21) Elias, B.; Creely, C.; Doorley, G. W.; Feeney, M. M.; Moucheron, C.; KirschDeMesmaeker, A.; Dyer, J.; Grills, D. C.; George, M. W.; Matousek, P.; Parker, A. W.; Towrie, M.; Kelly, J. M. Chem. A Eur. J. 2008, 14, 369.

(22) Gschwind, F.; Jansen, M. Acta. Crystallogr. 2012, E68, m1319.

(23) Lu, X.-J. Nucleic Acids Res. 2003, 31, 5108.

(24) Vargason, J. M.; Henderson, K.; Ho, P. S. Proc. Natl. Acad. Sci. U. S. A. 2001, 98, 7265.

(25) Niyazi, H.; Hall, J. P.; O’Sullivan, K.; Winter, G.; Sorensen, T.; Kelly, J. M.; Cardin, C. J. Nat. Chem. 2012, 4, 621.

(26) Kamitori, S.; Takusagawa, F. J. Mol. Biol. 1992, 225, 445.

(27) Hays, F. A.; Teegarden, A.; Jones, Z. J. R.; Harms, M.; Raup, D.; Watson, J.; Cavaliere, E.; Ho, P. S. Proc. Natl. Acad. Sci. USA. 2005, 102, 7157.

(28) Huang, C. C.; Couch, G. S.; Pettersen, E. F.; Ferrin, T. E. In Pacific Symposium on Biocomputing; 1996; p. 724.

(29) Pope, L. H.; Shotton, M. W.; Forsyth, V. T.; Langan, P.; Denny, R. C.; Giesen, U.; Dauvergne, M. T.; Fuller, W. Phys. B 1997, 241, 1156.

(30) Forsyth, V. T.; Mahendrasingam, A.; Pigram, W. J.; Greenall, R. J.; Bellamy, K.; Fuller, W.; Mason, S. A. Int. J. Biol. Macromol. 1989, 11, 236.

(31) Mandal, P. K.; Venkadesh, S.; Gautham, N. Acta. Crystallogr. 2012, F68, 393.

(32) Maehigashi, T.; Hsiao, C.; Kruger Woods, K.; Moulaei, T.; Hud, N. V; Dean Williams, L. Nucleic Acids Res. 2011, 40, 3714.

(33) Clark, G. R. Nucleic Acids Res. 2000, 28, 1259.

(34) Wheeler, M. J.; Russi, S.; Bowler, M. G.; Bowler, M. W. Acta. Crystallogr. 2012, F68, 111.

(35) Wang, H.; Yang, Y.; Schofield, M. J.; Du, C.; Fridman, Y.; Lee, S. D.; Larson, E. D.; Drummond, J. T.; Alani, E.; Hsieh, P.; Erie, D. A. Proc. Natl. Acad. Sci. U. S. A. 2003, $100,14822$. 
(36) Protozanova, E.; Yakovchuk, P.; Frank-Kamenetskii, M. D. J. Mol. Biol. 2004, 342, 775.

(37) Winston, P. W.; Bates, D. H. Ecology 1960, 41, 232.

(38) Nolin, F.; Michel, J.; Wortham, L.; Tchelidze, P.; Balossier, G.; Banchet, V.; Bobichon, H.; Lalun, N.; Terryn, C.; Ploton, D. Cell. Mol. Life Sci. 2013, 70, 2383.

(39) Russi, S.; Juers, D. H.; Sanchez-Weatherby, J.; Pellegrini, E.; Mossou, E.; Forsyth, V. T.; Huet, J.; Gobbo, A.; Felisaz, F.; Moya, R.; McSweeney, S. M.; Cusack, S.; Cipriani, F.; Bowler, M. W. J. Struct. Biol. 2011, 175, 236.

(40) Liu, C.; Jin, Q.; Lv, K.; Zhang, L.; Liu, M. Chem. Commun. 2014, 50, 3702.

(41) Greschner, A. A.; Bujold, K. E.; Sleiman, H. F. J. Am. Chem. Soc. 2013, 135, 11283.

(42) Winter, G. J. Appl. Crystallogr. 2009, 43, 186.

(43) Kabsch, W. Acta. Crystallogr. 2010, D66, 125.

(44) Evans, P. Acta. Crystallogr. 2006, D62, 72.

(45) McCoy, A. J.; Grosse-Kunstleve, R. W.; Adams, P. D.; Winn, M. D.; Storoni, L. C.; Read, R. J. J. Appl. Cryst. 2007, 40, 658.

(46) Murshudov, G. N.; Vagin, A. A.; Dodson, E. J. Acta. Crystallogr. 1997, D53, 240.

(47) Emsley, P.; Lohkamp, B.; Scott, W. G.; Cowtan, K. Acta. Crystallogr. 2010, D66, 486.

(48) Collaborative Computational Project Number 4. Acta. Crystallogr. 1994, D50, 760.

(49) Incardona, M.-F.; Bourenkov, G. P.; Levik, K.; Pieritz, R. A.; Popov, A. N.; Svensson, O. J. Synchrotron. Radiat. 2009, 16, 872. 


\section{TOC Graphic}

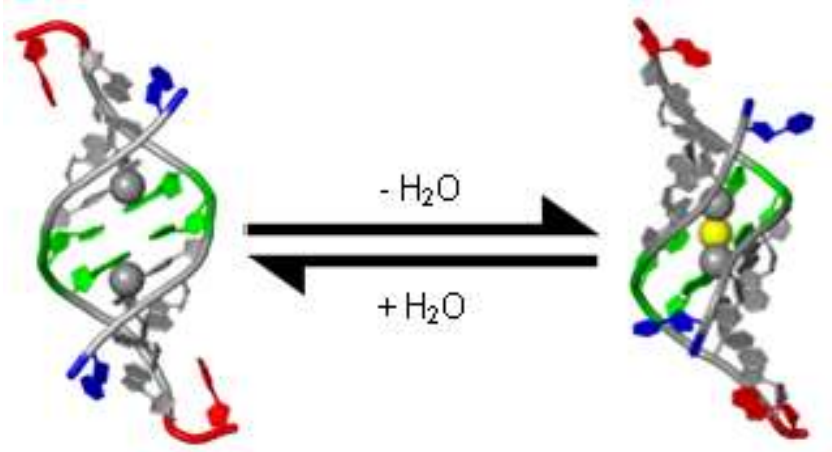

